\title{
Survival of leptospires in commercial blood culture systems revisited
}

\author{
M F Palmer, W J Zochowski
}

\begin{abstract}
Aim-To assess the ability of commercial blood culture systems to maintain leptospires.

Methods-Nine different commercial blood culture bottles were compared for their ability to maintain four leptospiral strains at two temperatures, $30^{\circ} \mathrm{C}$ and $37^{\circ} \mathrm{C}$. Bottles were subcultured at 48 hours, and one, two, three, and four week intervals and examined microscopically for the presence of viable leptospires.

Results-The results were comparable with those of an earlier study, which showed that different commercial blood culture systems varied in their ability to maintain leptospires.

Conclusions-No single factor appears to influence the viability of leptospires in blood culture systems. In general, the combination of an aerobic blood culture and an incubation temperature of $30^{\circ} \mathrm{C}$ enhances the viability of leptospires, and hence would increase the chances of their subsequent isolation from suspected cases of leptospiraemia.

(F Clin Pathol 2000;53:713-714)
\end{abstract}

Keywords: leptospirosis; blood; culture; viability

In human and animal infections leptospiraemia is considered to be of short duration. Normally organisms are only found in the blood during the first eight days of illness. ${ }^{1}$ Therefore, the time that a blood culture is taken after the development of symptoms in a suspected case of leptospirosis is an important factor in the subsequent isolation of that organism. Similarly, the initiation of appropriate chemotherapy will also influence the isolation rate. In addition, a study in 1984 revealed large differences in the ability of commercial blood culture systems to maintain various strains of leptospires. ${ }^{2}$ It is important to determine the suitability of these commercial blood culture systems to maintaining leptospires because no other maintenance or culture media are

Accepted for publication 26 April 2000 available in routine laboratories in the UK for the isolation of the organism from suspected cases of leptospiraemia. Therefore, all suspected cases of leptospirosis where culture is attempted are referred to the reference facility. The most readily available clinical sample is usually a blood culture; therefore, we need to know whether the blood culture sent to the reference laboratory is able to maintain leptospires to enhance the chances of their isolation using conventional culture methods. The introduction of automated blood culture systems into most microbiology laboratories has had a major influence on the investigation of suspected cases of bacteraemia and septicaemia. Therefore, we thought it appropriate to investigate the survival times of leptospiral strains in some of these "newer" blood culture systems, and compare them with some of those examined in the previous study.

\section{Methods}

Four different leptospiral strains were incorporated into the study: Leptospira interrogans serovars: icterohaemorrhagiae, hardjo, bataviae and grippotyphosa. Serovars icterohaemorrhagiae and hardjo were chosen because they are the most common serovars causing human infection in the UK. Serovar bataviae is found mainly in Asia and serovar grippotyphosa in mainland Europe.

Each serovar was inoculated into Johnson and Harris's modification of Ellinghausen and McCullough's medium (EMJH) ${ }^{4}$ and incubated at $30^{\circ} \mathrm{C}$ for seven days. Each culture was checked for purity by culturing on blood agar at $37^{\circ} \mathrm{C}$ and $30^{\circ} \mathrm{C}$, and the numbers of leptospires/ml of culture medium were estimated using darkground microscopy and a Thoma counting chamber.

Blood from healthy seronegative adults was added aseptically to each blood culture bottle according to the manufacturer's recommendation (table 1). Each blood culture bottle was aseptically inoculated with the appropriate leptospiral strain, giving a final concentration of approximately $10^{5}$ leptospires $/ \mathrm{ml}$ of blood culture. Appropriate controls were included to monitor the viability of each strain throughout our study.

Blood cultures were incubated at $37^{\circ} \mathrm{C}$, simulating the conditions found in most routine microbiology laboratories, and also at $30^{\circ} \mathrm{C}$, the optimum temperature for the growth of pathogenic leptospires.

One drop $(50 \mu \mathrm{l})$ of blood from each blood culture system was aseptically removed and inoculated in duplicate into $3 \mathrm{ml}$ of leptospira isolation media (EMJH plus $2 \%$ rabbit serum 
Table 2 Duration of viability of Leptospira interrogans strains in aerobic blood culture systems

\begin{tabular}{|c|c|c|c|c|c|c|c|c|c|c|c|c|}
\hline \multirow[b]{2}{*}{ Serovar } & \multicolumn{2}{|l|}{ Vital } & \multicolumn{2}{|l|}{ Signal } & \multicolumn{2}{|c|}{$\begin{array}{l}\text { Southern } \\
\text { Group }\end{array}$} & \multicolumn{2}{|c|}{ BacT/Alert } & \multicolumn{2}{|c|}{ Pedi-Bact } & \multicolumn{2}{|c|}{ BACTEC } \\
\hline & $30^{\circ}$ & $37^{\circ}$ & $30^{\circ}$ & $37^{\circ}$ & $30^{\circ}$ & $37^{\circ}$ & $30^{\circ}$ & $37^{\circ}$ & $30^{\circ}$ & $37^{\circ}$ & $30^{\circ}$ & $37^{\circ}$ \\
\hline L icterohaemorrhagie & $4 \mathrm{wk}$ & $48 \mathrm{hr}$ & $48 \mathrm{hr}$ & $48 \mathrm{hr}$ & $7 \mathrm{wk}$ & $48 \mathrm{hr}$ & $1 \mathrm{wk}$ & $48 \mathrm{hr}$ & $1 \mathrm{wk}$ & $48 \mathrm{hr}$ & $3 \mathrm{wk}$ & $1 \mathrm{wk}$ \\
\hline$L$ hardjo & $4 \mathrm{wk}$ & $48 \mathrm{hr}$ & $48 \mathrm{hr}$ & $48 \mathrm{hr}$ & $7 \mathrm{wk}$ & $48 \mathrm{hr}$ & $1 \mathrm{wk}$ & - & $1 \mathrm{wk}$ & - & $3 \mathrm{wk}$ & $1 \mathrm{wk}$ \\
\hline$L$ ataviae & $3 \mathrm{wk}$ & $48 \mathrm{hr}$ & $48 \mathrm{hr}$ & - & $6 \mathrm{wk}$ & $48 \mathrm{hr}$ & - & - & $48 \mathrm{hr}$ & $48 \mathrm{hr}$ & $3 \mathrm{wk}$ & $48 \mathrm{hr}$ \\
\hline$L$ grippotyphosa & $4 \mathrm{wk}$ & $48 \mathrm{hr}$ & $48 \mathrm{hr}$ & - & $7 \mathrm{wk}$ & $48 \mathrm{hr}$ & $1 \mathrm{wk}$ & - & $1 \mathrm{wk}$ & $48 \mathrm{hr}$ & $3 \mathrm{wk}$ & $1 \mathrm{wk}$ \\
\hline
\end{tabular}

$48 \mathrm{hr}$ refers to $\geqslant 2$ days but $<7$ days.

-, No growth at $48 \mathrm{hr}$; hr, hours; wk, weeks.

and $0.1 \%$ agar). ${ }^{5} \mathrm{~A}$ further four serial dilutions were made from each of the original dilutions in isolation medium and all the bottles were incubated at $30^{\circ} \mathrm{C}$. These were then examined microscopically under dark ground illumination at weekly intervals for six weeks for the presence of viable leptospires.

The process of subculturing from the original blood culture systems was performed at 48 hours, and one, two, three, and four week intervals. Any blood culture still positive after four weeks incubation were incubated further and subcultured until becoming negative.

\section{Results}

Our results indicate that there is still a variation between different commercial blood culture systems in their ability to maintain leptospires. Of the "newer" systems, the Vital aerobic and anaerobic systems compared favourably against some of the other media, particularly when the bottles were incubated at $30^{\circ} \mathrm{C}$ (tables 2 and 3). The Southern Group glucose broth also gave good viability at $30^{\circ} \mathrm{C}$, confirming the results of the 1983 study. $^{2}$ Overall, most systems, particularly the aerobic bottles, gave enhanced viability times at $30^{\circ} \mathrm{C}$ compared with identical bottles that were incubated at $37^{\circ} \mathrm{C}$.

\section{Discussion}

The variation in the ability of commercial blood systems to maintain leptospires is likely to be the result of several factors.

Leptospires are chemo-organotrophic, using long chain fatty acids as their main source of carbon, and inorganic ammonium salts as their

Table 3 Duration of viability of Leptospira interrogans strains in anaerobic blood culture systems

\begin{tabular}{|c|c|c|c|c|c|c|}
\hline \multirow[b]{2}{*}{ Serovar } & \multicolumn{2}{|l|}{ Vital } & \multicolumn{2}{|c|}{ BacT/Alert } & \multicolumn{2}{|c|}{$B A C T E C$} \\
\hline & $30^{\circ}$ & $37^{\circ}$ & $30^{\circ}$ & $37^{\circ}$ & $30^{\circ}$ & $37^{\circ}$ \\
\hline L icterohaemorrhagiae & $4 \mathrm{wk}$ & $48 \mathrm{hr}$ & - & - & - & - \\
\hline$L$ hardjo & $4 \mathrm{wk}$ & $48 \mathrm{hr}$ & - & - & - & - \\
\hline$L$ bataviae & $4 \mathrm{wk}$ & $48 \mathrm{hr}$ & - & - & - & - \\
\hline L grippotyphosa & $4 \mathrm{wk}$ & $48 \mathrm{hr}$ & - & - & - & - \\
\hline
\end{tabular}

-, No growth at $48 \mathrm{hr}$; hr, hours; wk, weeks. major source of nitrogen. Therefore, the exacting chemical metabolic requirements of leptospires might account for the failure of some systems to maintain them. Variation in chemical formulation between some of the systems might affect their ability to maintain leptospires. As suggested in previous studies, even when systems have similar components there may be variations in some of the commercial peptones that make up these formulations.

It has been shown that the temperature of incubation is an important factor in the successful isolation of leptospires from blood culture systems. Those bottles incubated at $30^{\circ} \mathrm{C}$ clearly showed improved maintenance times compared with those incubated at $37^{\circ} \mathrm{C}$.

Another factor may be that, with the exception of the BacT/Alert aerobic and Pedi-Bact bottles, the viability studies were carried out on unvented preflushed bottles. Previous investigations have shown that venting of blood culture bottles can improve the isolation of some organisms. ${ }^{6}$ In addition, the preflushing of bottles, such as anaerobic blood culture bottles, with carbon dioxide and nitrogen appeared to be detrimental to the viability of leptospires in most blood culture systems tested in our study.

\section{Conclusion}

In general, the use of an aerobic blood culture bottle and an incubation temperature of $30^{\circ} \mathrm{C}$ significantly increases the chances of successful isolation from cases of suspected leptospiraemia.

1 Turner LH. Leptospirosis I. Trans $R$ Soc Trop Med Hyg 1967;61:842-55.

2 Palmer MF, Waitkins SA, Zochowski WJ. Survival of leptospires in commercial blood culture systems. Zentrabl Bakteriol Mikrobiol Hyg [A] 1984;257:480-7.

3 Gsell $O$. The changing epidemiology of leptospirosis in Europe. Zentrabl Bakteriol 1990;273:412-17.

4 Johnson RC, Harris VG. Growth at low temperatures. 7 Bacteriol 1967;94:27-31.

5 Turner LH. Leptospirosis II. Trans R Soc Trop Med Hyg 1968;62:880-98.

6 Gantz NM, Swain JL, Medieros AA, et al. Vacuum blood cultures inhibiting the growth of candida and fostering growth of bacteroides. Lancet 1974;6:1174-6. 